\title{
Changes in stigma among a cohort of people on antiretroviral therapy: Findings from Mombasa, Kenya
}

Susan Kaai

Avina Sarna

Population Council

Stanley Luchters

Scott Geibel

Population Council

Paul Munyao

See next page for additional authors

Follow this and additional works at: https://knowledgecommons.popcouncil.org/departments_sbsr-hiv

Part of the Demography, Population, and Ecology Commons, Family, Life Course, and Society

Commons, International Public Health Commons, and the Medicine and Health Commons

How does access to this work benefit you? Let us know!

\section{Recommended Citation}

Kaai, Susan, Avina Sarna, Stanley Luchters, Scott Geibel, Paul Munyao, Kishorchandra N. Mandaliya, Khadija Shikely, Marleen Temmerman, and Naomi Rutenberg. 2007. "Changes in stigma among a cohort of people on antiretroviral therapy: Findings from Mombasa, Kenya," Horizons Research Summary. Nairobi: Population Council. 


\section{Authors}

Susan Kaai, Avina Sarna, Stanley Luchters, Scott Geibel, Paul Munyao, Kishorchandra N. Mandaliya, Khadija Shikely, Marleen Temmerman, and Naomi Rutenberg 


\section{Changes in Stigma among a Cohort of People on ANTIRETROVIRAL ThERAPy: FINDINGS FROM MOMBASA, KENYA}

A longitudinal study of patients on antiretroviral therapy (ART) found that levels of internalized stigma decreased after 12 months on treatment. Participants also disclosed to a greater number of family members. Despite these positive changes, internalized stigma remains a problem for many respondents and warrants increased stigma reduction activities in the community.

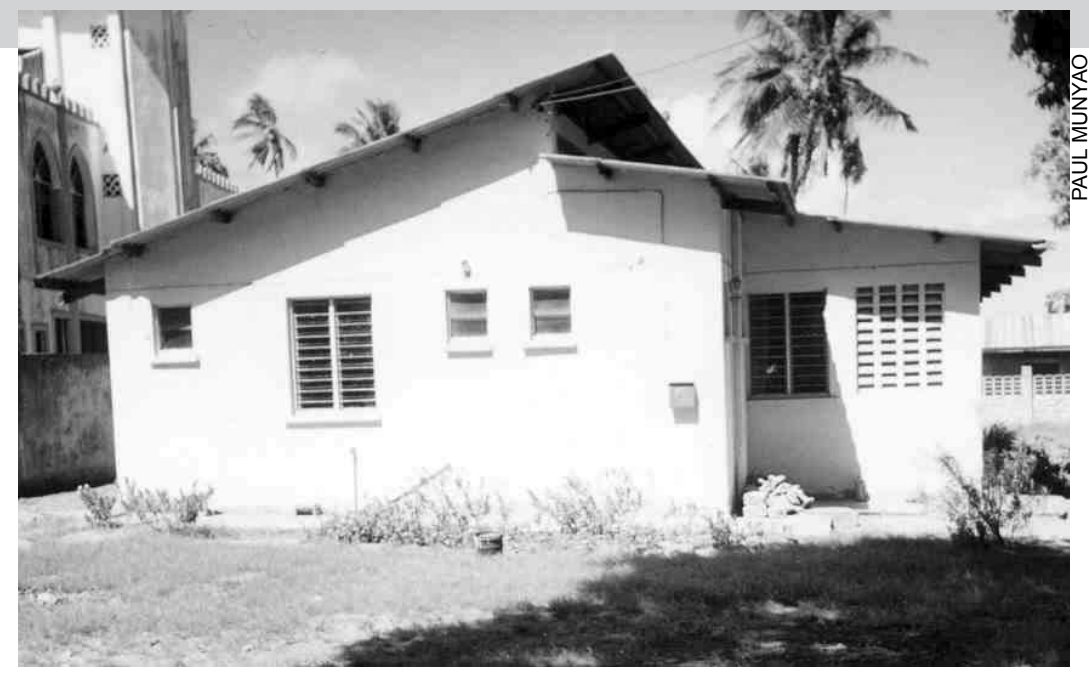

Bamburi Health Centre in Mombasa where study respondents accessed ART.
0 tigma has been a reality in the lives of people living with HIV (PLHIV) since the inception of the AIDS epidemic. PLHIV have reported experiencing stigma in a variety of ways including isolation, rejection, withholding of emotional and financial support, denial of health services, and loss of employment. These manifestations of stigma can have profound implications for the health, psychosocial well-being, and utilization of health services by PLHIV (UNAIDS 2001; Alubo et al. 2002).

In the industrialized world, the availability of ART and a subsequent change in perception of AIDS as a chronic manageable disease has coincided with a decrease in stigma and discrimination directed toward PLHIV. However, little is known in developing countries about whether perceptions and experiences of stigma among PLHIV have changed following increased access to ART.

In response to this gap, researchers from the Horizons Program and the International Centre for Reproductive Health undertook an observational study in Mombasa, Kenya, to document changes in internalized and experienced stigma in a cohort of HIV-infected persons over a 12-month period after initiating ART. The study was conducted in collaboration with Coast Province General Hospital, Mkomani Bomu Clinic, and Port Reitz District Hospital.

To read more about this study, go to www.popcouncil.org/horizons/projects/Kenya_HAARTMombasa.htm 


\section{Methodology}

The researchers conducted semi-structured interviews at health facilities with a cohort of HIV-infected persons prior to starting ART and after 12 months on treatment. The interviewers were trained in building rapport, maintaining confidentiality, and using non-judgemental data collection techniques. All patients received standard adherence counseling consisting of three preparatory sessions before the initiation of ART and ongoing counseling for the duration of the study.

Internalized stigma was measured using a 16-item scale (Cronbach's alpha 0.81 ; possible range of scores 16-64) adapted from the HIV Stigma scale (Berger, Ferrans, and Lashley 2001). The scale covered four domains: personalized stigma, disclosure concerns, negative self-image, and concern with public attitudes toward PLHIV. Using a 4-point Likert scale, respondents indicated their level of agreement with each item (strongly disagree, disagree, agree, and strongly agree). The scores were categorized into minimal to low stigma (16-40) and moderate to high stigma (41-64). Experienced stigma within the family, community, and workplace was assessed by asking respondents about people's reactions after they disclosed their HIV status in these settings. Respondents were also asked whether they received any form of support or encouragement from these individuals.

The Ethical Review Board of Kenyatta National Hospital, Kenya, and the Institutional Review Board of the Population Council, USA, gave ethical approval for the study. All interviewees provided informed consent prior to the interviews.

\section{Sociodemographic Characteristics}

A total of 181 participants were followed over 12 months and completed both baseline and endline interviews. Most of the sample was female (63 percent). The mean age was 37 years (SD 7.93) and 84 percent had completed primary school. Almost half (48 percent) were married or cohabitating, 15 percent were single, 14 percent were divorced or separated, and 23 percent were widowed.

\section{Key Findings}

Internalized stigma declined significantly after 12 months on treatment, particularly among women. Nearly three-quarters (73 percent) of respondents reported moderate to high internalized stigma at baseline. As shown in Figure 1, the proportion reporting moderate to high internalized stigma declined significantly after 12 months on treatment $(\mathrm{p}<.001)$; correspondingly, the proportion reporting minimal to low stigma increased significantly at follow up.

At baseline more women than men reported moderate to high internalized stigma ( 71 vs. 65 percent). After 12 months on treatment, there were significant declines in the proportion of both women (71 vs. 60 percent; $p$ $=0.018)$ and men ( 65 vs. 51 percent; $\mathrm{p}=0.007)$ who reported moderate to high internalized stigma.

When examining mean scores to measure internalized stigma, women reported significantly higher mean scores compared to men at baseline ( 45.7 vs. 43.3 ; p $=0.035)$. The mean scores declined for both groups, although the decline was greater among women. At follow up, women and men had similar mean scores ( 41.78 vs. $40.34 ; \mathrm{p}=0.215$ ).

There was no association between internalized stigma and age or marital status.

\section{Figure 1 Classification of participants by internalized stigma scores at baseline and follow up}

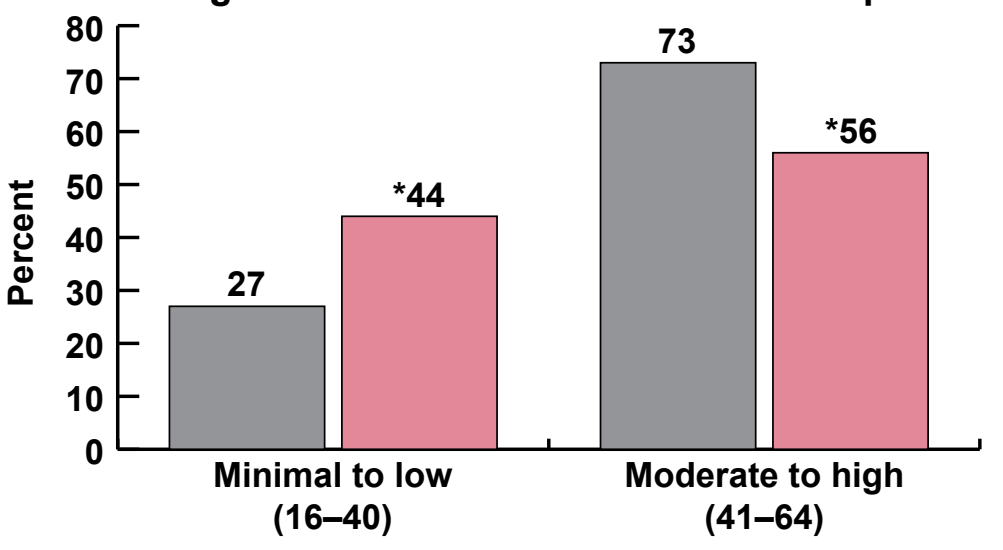

Baseline ( $n=183)$ Follow up $(n=181)$

${ }^{*} p=0.001$ 
Participants disclosed to a significantly greater number of family members after 12 months on treatment. At baseline, the vast majority (85 percent) of respondents had disclosed their HIV status to someone in the family. While this increased slightly to 90 percent, the difference was not statistically significant. But the number of family members to whom participants had disclosed their HIV status increased significantly over time from a median of two family members at baseline to a median of three family members at follow up $(\mathrm{p}<$ $0.001)$.

Among married or cohabiting respondents disclosure to spouses was high at baseline ( 80 percent; $\mathrm{n}=101$ ) and at follow up (83 percent; $n=88$ ). Figure 2 shows changes in disclosure rates to other family members. At both baseline and endline, disclosure was most often to siblings and parents. Disclosure to all categories of family members increased at endline, but the difference was only statistically significantly to parents $(\mathrm{p}=0.05)$ and children $(\mathrm{p}=0.004)$.

\section{Positive support from family members was very high at baseline and remained high at endline. Study par-} ticipants who had disclosed their HIV status to family members were asked about their relatives' reactions at baseline and endline. During both interviews, nearly all respondents reported that they had received positive support from at least one family member. Emotional support was the most frequently reported type of support the participants received followed by financial support and physical care. Siblings and spouses/partners were the most frequently cited source of support in the family. Less than 10 percent reported having experienced a negative reaction from a family member. These included "don't visit me," "don't touch me," "don't eat or sit with me," "deserted me," "verbally abused me," "threw me out of the house," and "hid me in a corner."

\footnotetext{
There was no change in disclosure rates to community members. At baseline, only about a fourth of respondents disclosed to a community member and there was little change at endline. Study participants mainly disclosed to friends, neighbors, and religious leaders. The proportion of respondents disclosing their HIV status to a neighbor, health worker, and in a PLHIV support group increased after 12 months on treatment, but the differences were not statistically significant.
}

Figure 2 Disclosure to family members at baseline and follow up

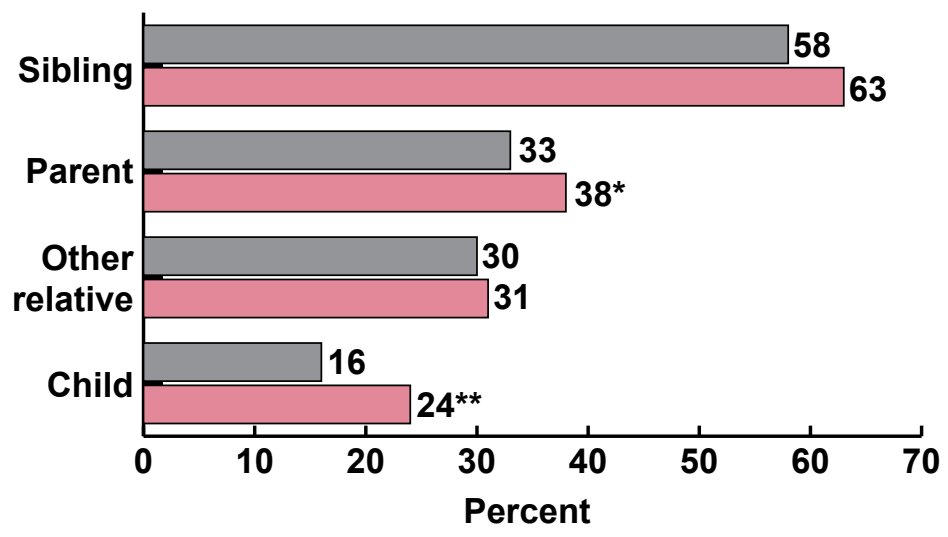

\section{$\square$ Baseline ( $n=154) \quad \square$ Follow up ( $=163)$}

${ }^{*} p=0.05 ;{ }^{* *} p=0.004$

Note: Multiple responses permitted

Most respondents who had disclosed to someone in the community reported that they had received some form of support; less than 10 percent reported a negative reaction. Very few respondents (less than 4 percent) who disclosed their HIV status to someone in the community reported experiencing a stigmatizing event in public, such as being called a derogatory name or being refused service in a restaurant.

The most frequently mentioned reasons at baseline for not disclosing their HIV status to someone in the community were fear of verbal abuse, gossip, and being isolated and these fears did not diminish at endline. Although it not a principal reason for not disclosing, the proportion of respondents who feared that they or their family would be rejected decreased significantly at endline (15 vs. 5 percent; $\mathrm{p}=0.035$ ).

Disclosure at the workplace was low, yet participants received positive support from the individuals they disclosed to. At baseline 30 percent $(n=54)$ of the respondents were employed. This figure increased to 35 percent $(n=64)$ a year later. Disclosure to colleagues at work by employed respondents increased from 15 percent at baseline to 22 percent at endline, but the difference was not statistically significant. Overall, colleagues and employers were supportive of participants, who had dsiclosed providing mostly psychological and physical support. The most commonly mentioned reasons for not disclosing at the workplace were fear 
of rumors/gossip, fear of isolation, and fear of losing their job. Overall, there were no significant differences between baseline and endline regarding the reasons for not disclosing in the workplace, except for a significant decrease in fear of verbal abuse (17 vs. 6 percent; $\mathrm{p}<$ $0.05)$.

\section{Conclusions}

The study found that levels of internalized stigma decreased among participants. Before initiating ART, many study participants reported a moderate to high level of internalized stigma. However, after 12 months on ART, the proportion of patients in this category declined significantly. In addition, the study revealed that participants disclosed to a significantly greater number of family members over time, especially to children.

But there was no change in disclosure rates in the community or at the workplace.

Only a small proportion of participants reported experiencing a negative or stigmatizing event in the family, community, or at the workplace. Within the family nearly all participants reported receiving psychological, financial, and/or physical support. Fears of rejection by the community and of verbal abuse at the workplace declined significantly at follow up.

Due to a lack of a control group, it is not possible to conclude that access to ART reduced internalized stigma and increased disclosure to more family members. But the data do indicate a strong association between initiation of ART and more favorable stigma and disclosure outcomes. A possible explanation for this association is that being on ART improved participants' physical health, which contributed to improvements in their self-image and self-worth, and reductions in their fears of disclosure and negative public attitudes. It is also likely that ongoing stigma-reduction efforts in Mombasa, such as red-ribbon campaigns and information dissemination about transmission, have contributed to the study's positive outcomes.
In this particular setting where access to ART has increased greatly, family members appear to be the easiest for participants to approach to disclose their serostatus, whereas the community and workplace remain much more formidable outlets. More research using qualitative methods is needed to better understand the reasons for non-disclosure in the community with regard to privacy and trust issues, and expectations of support from workmates and the community.

Finally, although the researchers observed a reduction in internalized stigma, a substantial proportion of both women and men reported moderate to high levels at follow up. Therefore, in addition to increased and sustained availability of ART, more stigma reduction interventions are warranted in this community. $\mathcal{R}$

December 2007

\section{References}

Alubo, O. et al. 2002. "Acceptance and stigmatization of PLHA in Nigeria," AIDS Care 14(1): 117-126.

Berger, Barbara E., Carol E. Ferrans, and Felissa R. Lashley. 2001. "Measuring stigma in people with HIV: Psychometric assessment of the HIV stigma scale," Research in Nursing and Health 24: 518-529.

UNAIDS. 2001. "Uganda: HIV and AIDS related discrimination, stigmatization and denial." Geneva: UNAIDS.

Investigators for this study were Stanley Luchters of the International Centre for Reproductive Health (ICRH), Avina Sarna and Susan Kaai of Horizons/Population Council. Intervention and study partners include Horizons, ICRH, Coast Province General Hospital, Mkomani Bomu Clinic, Port Reitz District Hospital, FHI/IMPACT, MSH/RPM Plus, and Kenya Ministry of Health.

For more information on this study please contact Avina Sarna (asarna@popcouncil.org) or Stanley_Luchters (Stanley.Luchters@icrh.org)

Suggested citation: Kaai, Susan, Avina Sarna, Stanley Luchters, Scott Geibel, Paul Munyao, Kishor Mandaliya, Khadija Shikely, Marleen Temmerman and Naomi Rutenberg. 2007. "Changes in stigma among a cohort of people on antiretroviral therapy: Findings from Mombasa, Kenya," Horizons Research Summary. Nairobi: Population Council.

\section{Hprizons N}

Population Council/Horizons

Communications Unit

4301 Connecticut Avenue, NW

Suite 280

Washington, DC 20008

\section{(P) Population Council}

Tel: $202-237-9400$

Fax: 202-237-8410

horizons@popcouncil.org

www.popcouncil.org/horizons
This research summary is made possible by the generous support of the American people through the United States Agency for International Development (USAID) and the President's Emergency Plan for AIDS Relief under the terms of HRN-A-00-97-00012-00. The contents are the responsibility of the Horizons Program and do not necessarily reflect the views of USAID or the United States Government. 